Check for updates

Cite this: Phys. Chem. Chem. Phys., 2020, 22, 11348

Received 9th March 2020,

Accepted 21st April 2020

DOI: $10.1039 / \mathrm{d} 0 \mathrm{cp} 01321 \mathrm{~h}$

rsc.li/pccp

\title{
Stabilisation of dianion dimers trapped inside cyanostar macrocycles $\dagger$
}

\author{
Luis Miguel Azofra, (D) *ab José Elguero (iD ${ }^{c}$ and Ibon Alkorta (D) *c
}

Interanionic $\mathrm{H}$-bonds (IAHBs) are unfavourable interactions in the gas phase becoming favoured when anions are in solution. Dianion dimers are also susceptible to being trapped inside the cavities of cyanostar (CS) macrocycles, and thus, the formation of $2: 2$ anion: cyanostar aggregates is mainly supported by three kinds of interactions: IAHBs between the dianions, $\pi-\pi$ stacking between the confronted cyanostars, and the presence of an intricate network of multiple $\mathrm{C}\left(\mathrm{sp}^{2}\right) \mathrm{H} \ldots \mathrm{O} \mathrm{H}$-bonds between cyanostar ligands and the anionic moieties. An analysis of the interaction energies supported by NBO reveals a slight cooperative effect of the CSs on the IAHB stabilisation.

\section{Introduction}

Although non-covalent interactions are weak in general, there is no doubt about the fundamental role they play in diverse fields such as biological, environmental, and materials sciences, amongst others. Purine and pyrimidine bases in the DNA chains are held together by H-bonds, ${ }^{1}$ and these forces are also responsible for promoting protein folding and molecular recognition. ${ }^{2}$ The ability of geckos to walk up and down on vertical surfaces has been evidenced as van der Waals adhesion, ${ }^{3}$ and the fact that short-chain hydrocarbons are in the liquid state at room temperature is due to the existence of London dispersion forces.

The types of non-covalent interactions are diverse. Caused by electronic anisotropy, several dipole-dipole interactions have been described in a multitude of molecular systems: from halogen, ${ }^{4,5}$ chalcogen, ${ }^{6,7}$ or pnictogen ${ }^{8,9}$ bonds to tetrel ${ }^{10,11}$ or aerogen ${ }^{12}$ interactions, based on the atom acting as the Lewis acid. ${ }^{13}$ However, H-bonds ${ }^{14-16}$ remain the most studied dipoledipole force due to their ubiquitous presence and implications.

Intercationic $\mathrm{H}$-bond (ICHB) complexes have been observed experimentally in homo- and hetero-aggregates of peptides ${ }^{17}$ as well as in betaine gas-phase clusters. ${ }^{18}$ Together with

\footnotetext{
${ }^{a}$ CIDIA-FEAM (Unidad Asociada al Consejo Superior de Investigaciones Cientificas, CSIC, avalada por el Instituto de Ciencia de Materiales de Sevilla, Universidad de Sevilla), Instituto de Estudios Ambientales y Recursos Naturales (i-UNAT), Universidad de Las Palmas de Gran Canaria (ULPGC), Campus de Tafira, 35017, Las Palmas de Gran Canaria, Spain. E-mail: luismiguel.azofra@ulpgc.es

${ }^{b}$ Departamento de Quimica, Universidad de Las Palmas de Gran Canaria (ULPGC), Campus de Tafira, 35017, Las Palmas de Gran Canaria, Spain

${ }^{c}$ Instituto de Química Médica (IQM), Consejo Superior de Investigaciones

Cientificas (CSIC), Juan de la Cierva, 3, E-28006, Madrid, Spain.

E-mail: ibon@iqm.csic.es

$\dagger$ Electronic supplementary information (ESI) available: Optimised Cartesian coordinates. See DOI: 10.1039/d0cp01321h
}

interanionic H-bond (IAHB) complexes, these types of adducts have also been studied theoretically ${ }^{19-22}$ demonstrating a series of unique features such as the appearance of a transition state during the dissociation process that prevents them from being detached. ${ }^{23,24}$

Contrary to the assumption that anions cannot be held together due to the electrostatic repulsion, Novoa and co-workers corroborated the presence of inter-anionic $\mathrm{O}^{-} \mathrm{H}^{-} \cdots \mathrm{O}^{-}$bonds in potassium hydrogen oxalate crystals behaving as "tugboat" interactions that control the anion aggregation and minimise the anionic repulsions. ${ }^{25}$ This molecular linkage, assumed as a special kind of strong H-bond, was later classified as conventional. ${ }^{26-28}$

In recent years, a rich chemistry focused on anion recognition has been developed. ${ }^{29-33}$ In 2016, we reported a set of bistriazolium-based receptors with capabilities to include and stabilise $\mathrm{H}$-bonded dimers of $\mathrm{HP}_{2} \mathrm{O}_{7}{ }^{3-}, \mathrm{H}_{2} \mathrm{PO}_{4}{ }^{-}$, and $\mathrm{SO}_{4}{ }^{2-}$ anions. ${ }^{34}$ Based on these results, we were also able to identify selective behaviours in the affinity of a given receptor in capturing-encapsulating a given anion to the detriment of others. Two years later, we also described a tetracyclic cyclophane receptor containing two imidazolium rings capable of capturing single and dimeric phosphates and $\mathrm{PF}_{6}{ }^{-}$anions. ${ }^{35}$

Inspired by the design of cation-driven polymers, Flood and co-workers have recently reported the unprecedented synthesis of supramolecular anion-based polymers consisting of anionic phosphonates and cyanostar (CS) macrocycles. ${ }^{36}$ Encouraged by our interest in the understanding of the interactions explaining the stability of these complexes, herein we report a complete DFT study analysing the structures, energies, topology, and orbital interactions in a set of dianions supported by interanionic H-bonds (IAHBs) and their relative 2:2 stoichiometric anion: cyanostar adducts, where the anionic moieties include phosphonates and a series of common oxyacids. In this sense, our work provides a complete view about the stabilisation of 
complex systems where their constituent units are supported by a series of multiple weak interactions.

\section{Computational details}

A set of dianion dimers and their relative 2:2 stoichiometric anion : cyanostar complexes have been studied through the use of Density Functional Theory (DFT) via the spin-restricted Kohn-Sham (RKS) formalism and the PBE0 functional. ${ }^{37}$ Optimisation calculations were carried out in the gas phase using the $6-31+G(d)$ basis set for those atoms constituting the anionic moieties and the interacting hydrogens in the cyanostars, and the $3-21 \mathrm{G}$ basis set for the rest. ${ }^{38}$ The nature of the stationary points was corroborated through frequency calculations to ensure that the optimised structures correspond to true minima, i.e., with no imaginary frequencies. These optimised structures have been used for subsequent re-optimisations at the PBE0/6-31+G(d)/6-31G level of theory using the COSMO model for dichloromethane $(\varepsilon=9.0)$ and water $(\varepsilon=78.0)$ to simulate the solvent effects. ${ }^{39}$ Note that for As and Se atoms, the SVP basis set has been employed. ${ }^{40}$ All optimisation calculations were carried out using a fine grid and through the facilities provided by the NWChem package (version 6.8). ${ }^{41}$ For natural bond orbital (NBO) analysis, ${ }^{42}$ the NBO6.0 and Gaussian09 (revision D.01) ${ }^{43}$ programs have been used. Finally, atoms in molecules (AIM) analysis has been carried out with the AIMAll program. ${ }^{44}$

\section{Results and discussion}

A dimer composed of two units of hydrogen methylphosphonate is produced by the presence of two interanionic $\mathrm{H}$-bonds (IAHBs) (see Fig. 1). ${ }^{24}$ The gas-phase $\mathrm{CH}_{3} \mathrm{PO}_{3} \mathrm{H}^{-} \cdots \mathrm{CH}_{3} \mathrm{PO}_{3} \mathrm{H}^{-}$dimer exhibits an IAHB $\mathrm{O} \cdots \mathrm{H}$ distance of $1.69 \AA$ for its $C_{\mathrm{i}}$-symmetrised complex and a positive electronic interaction energy of $25.8 \mathrm{kcal} \mathrm{mol}^{-1}$, clearly indicating the non-favoured nature of this interaction. However, in dichloromethane $(\varepsilon=9.0)$ and water $(\varepsilon=78.0)$ solutions, this $C_{\mathrm{i}}$ minimum becomes favoured, with interaction energies of $-\mathbf{1 1 . 7}$ and $-15.6 \mathrm{kcal} \mathrm{mol}^{-1}$, corroborating that the higher the dielectric constant, the higher the stabilisation. ${ }^{45}$

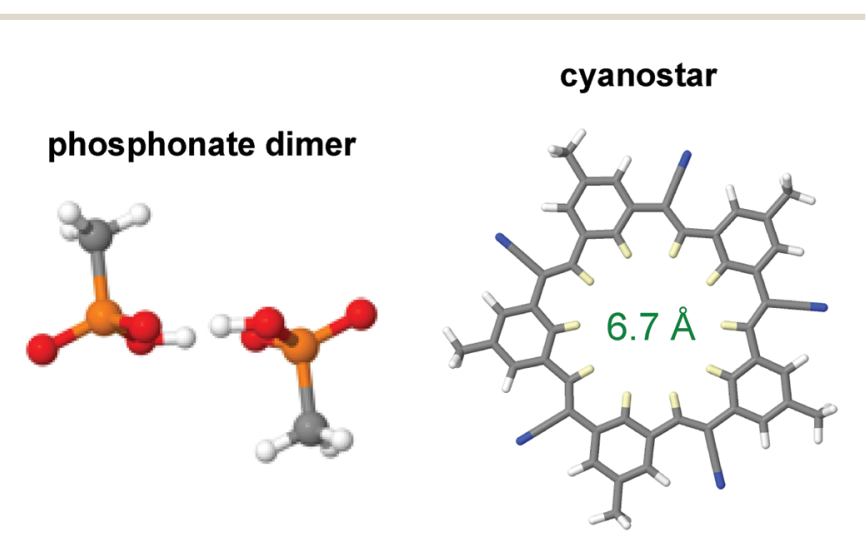

Fig. $1 \mathrm{H}$-Bonded dimer of hydrogen methylphosphonate (left) and cyanostar (CS) macrocycle composed of five cyano-stilbene units (right). Note: acidic hydrogens in CS are coloured in light yellow.
In addition, the IAHB distances decrease to $1.61 \AA$ in both solvents.

Recently reported by Flood et al., ${ }^{36}$ cyanostar (CS) macrocycles composed of five cyano-stilbene units ${ }^{46}$ can interact with phosphonates in order to form $2: 2$ stoichiometric supramolecular polymers. Although they have reported a CS ligand in which the phenyl rings were functionalised with tert-butyl groups, we have substituted them with methyl groups in order to simplify the models. Based on our calculations, the CS shows a circumferential hole of $6.7 \AA$ in diameter, this being measured as the average of the $\mathrm{H}-\mathrm{H}$ longer distances. The existence of this hole together with the acidic nature of the hydrogen atoms in the $\mathrm{CH}$ groups pointing inwards (coloured in light yellow at Fig. 1) provide an adequate environment for the interaction with anions. The formation of 2:2 anion:cyanostar aggregates includes the H-bonded dimer composed of two units of hydrogen methylphosphonate with two $\pi$-stacked CS ligands with eclipsed methyl and cyano groups. To build this, the X-ray structure of the $2: 2$ anion : cyanostar polymer with the $\mathrm{C}_{12} \mathrm{H}_{24}$ aliphatic linker has been used. ${ }^{36}$ The acidic hydrogens point towards the $\mathrm{O}$ atoms that support the negative charge. Fig. 2 displays the side and top views of the optimised minimum in dichloromethane solvent, as was reported in Flood's experiments. ${ }^{36}$

Three quantities for evaluating the electronic interaction energies have been considered:

$$
\begin{gathered}
E_{\text {int }}^{(1)}=E_{\text {complex }}-E_{\mathrm{PP}: \mathrm{CS}, \mathrm{a}}-E_{\mathrm{PP}: \mathrm{CS}, \mathrm{b}} \\
E_{\text {int }}^{(2)}=E_{\text {complex }}-E_{\mathrm{PP}, \mathrm{a}}-E_{\mathrm{CS}, \mathrm{a}}-E_{\mathrm{PP}, \mathrm{b}}-E_{\mathrm{CS}, \mathrm{b}} \\
E_{\mathrm{int}}^{(3)}=E_{\text {complex }}-E_{\mathrm{PP}: \mathrm{PP}}-E_{\mathrm{CS}: \mathrm{CS}}
\end{gathered}
$$

where 'complex' refers to the 2:2 phosphonate: cyanostar aggregate, 'PP' and 'CS' to the phosphonate and cyanostar monomers, and 'PP : CS', 'PP : PP', and 'CS : CS' to the respective dimeric structures. In all cases, the energies of monomers and $1: 1$ aggregates have been computed for their structures as in the complex. Note that ' $a$ ' and ' $b$ ' denote isoatomic units.

\section{2:2 phosphonate:cyanostar aggregate}
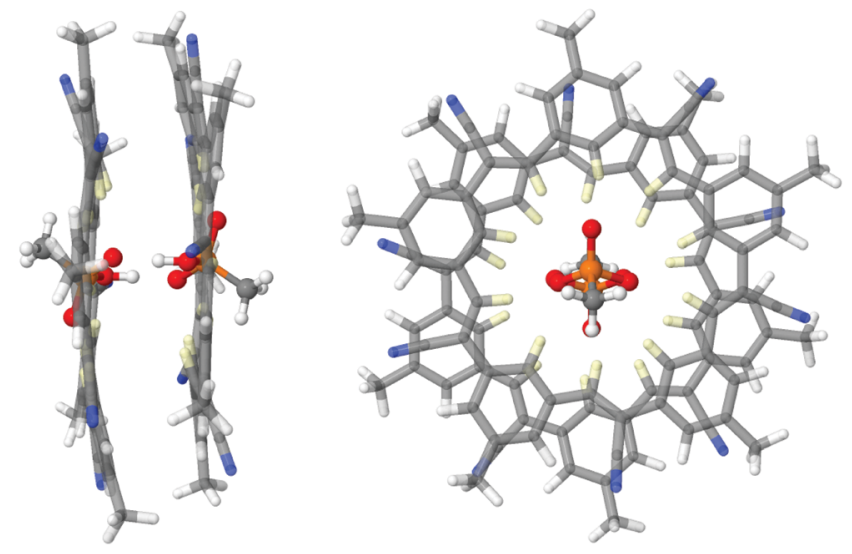

Fig. 2 Side and top views of the 2:2 stoichiometric phosphonate: cyanostar complex modelled in dichloromethane. 
$E_{\text {int }}^{(1)}$ represents the electronic energy released when the $2: 2$ complex is formed from its 1:1 stoichiometric phosphonate: cyanostar units. Thus, $E_{\text {int }}^{(1)}$ accounts for two types of interactions: the two interanionic H-bonds linking the phosphonate units and the $\pi-\pi$ stacking between the two cyanostars. On the other side, $E_{\text {int }}^{(2)}$ represents the electronic energy released when assembling the entire quadruplex from its constituent monomers, which also accounts for the $\mathrm{H}$-bonds between acidic hydrogens in CSs and the $\mathrm{O}$ atoms. This latter contribution can be approximated by subtracting the $E_{\mathrm{int}}^{(2)}\left(-37.6 \mathrm{kcal} \mathrm{mol}^{-1}\right)$ from the $E_{\text {int }}^{(1)}\left(-25.7 \mathrm{kcal} \mathrm{mol}^{-1}\right)$ quantities, resulting in $-11.9 \mathrm{kcal} \mathrm{mol}^{-1}$, a close value to $E_{\mathrm{int}}^{(3)}=-16.3 \mathrm{kcal} \mathrm{mol}^{-1}$, which formally represents the stabilisation due to the presence of the $\mathrm{C}\left(\mathrm{sp}^{2}\right) \mathrm{H} \cdots \mathrm{O} \mathrm{H}$-bonds. In order to evaluate which amount of $E_{\text {int }}^{(1)}$ is due to the IAHBs and which to the $\pi-\pi$ stacking, the $E_{\mathrm{int}}^{(\mathrm{PH})}$ and $E_{\mathrm{int}}^{(\mathrm{CS})}$ quantities have been evaluated. The first, $E_{\mathrm{int}}^{(\mathrm{PH})}=$ $-12.6 \mathrm{kcal} \mathrm{mol}^{-1}$, is ca. $1 \mathrm{kcal} \mathrm{mol}^{-1}$ more favoured than the interaction of the isolated phosphonate dianion in dichloromethane solution. Finally, the potential binding effect exerted by the $\pi-\pi$ stacking amongst the confronted CSs has been estimated to be $-8.7 \mathrm{kcal} \mathrm{mol}^{-1}$, judging by the value of $E_{\mathrm{int}}^{(\mathrm{CS})}$ (see Table 1).

$$
\begin{gathered}
E_{\mathrm{int}}^{(\mathrm{PH})}=E_{\mathrm{PH}: \mathrm{PH}}-E_{\mathrm{PH}, \mathrm{a}}-E_{\mathrm{PH}, \mathrm{b}} \\
E_{\mathrm{int}}^{(\mathrm{CS})}=E_{\mathrm{CS}: \mathrm{CS}}-E_{\mathrm{CS}, \mathrm{a}}-E_{\mathrm{CS}, \mathrm{b}}
\end{gathered}
$$

For analysing the effect of different solvents on the stabilisation of the $2: 2$ phosphonate : cyanostar aggregates, the system was also optimised in water solution. First and concerning the common features, a very similar structure with a root mean square (rms) of just $0.31 \AA$ is observed. In this sense, $E_{\text {int }}^{(\mathrm{CS})}$, signifying the $\pi-\pi$ stacking interaction, accounts for $-8.7 \mathrm{kcal} \mathrm{mol}^{-1}$, which is exactly the same value as the one observed in dichloromethane solution. In addition, the interaction energy of the dianions, $E_{\mathrm{int}}^{(\mathrm{PH})}$, is calculated to be $-17.3 \mathrm{kcal} \mathrm{mol}{ }^{-1}$, being $1.7 \mathrm{kcal} \mathrm{mol}^{-1}$ more favoured than the interaction of the isolated dianion in aqueous solution. Based on these data, the slight cooperative effect that water exerts on the stabilisation of the IAHBs can be observed. Surprisingly, $E_{\text {int }}^{(1)}$ and $E_{\text {int }}^{(2)}$ only differ by $0.3 \mathrm{kcal} \mathrm{mol}^{-1}$, and therefore $E_{\text {int }}^{(3)}$ exhibits a quite small value of $-1.6 \mathrm{kcal} \mathrm{mol}^{-1}$. This does not mean that $\mathrm{C}\left(\mathrm{sp}^{2}\right) \mathrm{H} \cdots \mathrm{O} \mathrm{H}$-bonds are unfavourable interactions in water solution. Actually, the water stabilising effect on these acidic hydrogens in the free cyanostar has practically the same effect as that when cyanostars are complexed with the $\mathrm{O}$ atoms in phosphonates. Thus, a differentiating behaviour can be observed between a solvent with a low dielectric constant, as is the case of dichloromethane, versus another with a high dielectric constant, as it is with water.

Table 1 Interaction electronic energies $\left(\mathrm{kcal} \mathrm{mol}^{-1}\right)$ for the $2: 2$ phosphonate: cyanostar minimum

\begin{tabular}{llllll}
\hline Solvent & $E_{\text {int }}^{(1)}$ & $E_{\text {int }}^{(2)}$ & $E_{\text {int }}^{(3)}$ & $E_{\text {int }}^{(\mathrm{PH})}$ & $E_{\text {int }}^{(\mathrm{CS})}$ \\
\hline $\mathrm{CH}_{2} \mathrm{Cl}_{2}$ & -25.7 & -37.6 & -16.3 & -12.6 & -8.7 \\
$\mathrm{H}_{2} \mathrm{O}$ & -27.4 & -27.7 & -1.6 & -17.3 & -8.7
\end{tabular}

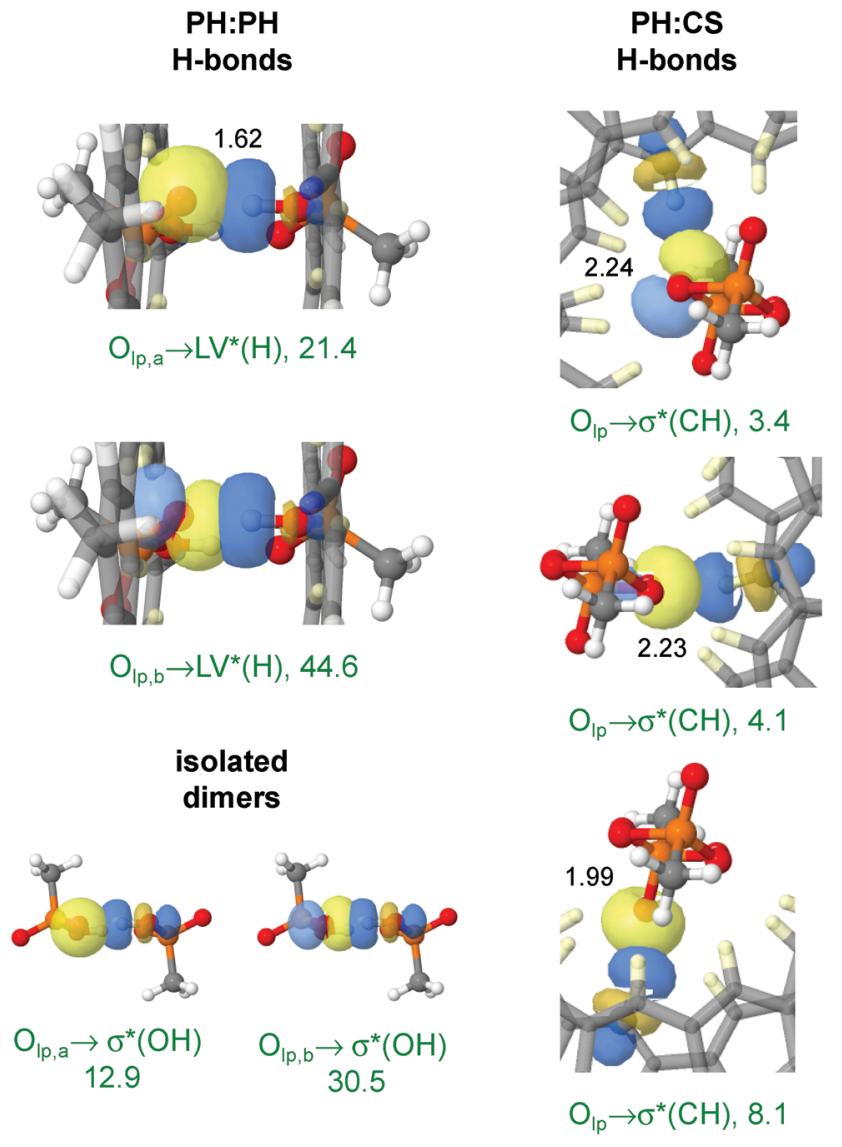

Fig. 3 Most representative NBO interactions for $\mathrm{H}$-bonds explaining the stability of the phosphonate: cyanostar minimum (in dichloromethane) shown in Fig. 2. Orbital interaction energies (green) are shown in $\mathrm{kcal} \mathrm{mol}^{-1}$ and $\mathrm{H}$-bond distances (black) in $\AA$.

Fig. 3 displays the most important natural bond orbital (NBO) interactions for the 2:2 phosphonate:cyanostar minimum shown in Fig. 2. Due to the $C_{\mathrm{i}}$ symmetry of this supramolecular adduct, these interactions are equal for both $\mathrm{PH}$ : CS moieties.

The lone pairs of the $\mathrm{O}$ atom that is actively participating as Lewis base in the IAHBs contribute to the establishment of two very strong orbital interactions with the lone vacant $\left(\mathrm{LV}^{*}\right) \mathrm{H}$ orbitals of the neighbouring phosphonate. Orbital interaction energies, $E^{(2)}$, have been calculated to be 21.4 and $44.6 \mathrm{kcal} \mathrm{mol}{ }^{-1}$. For comparison, $E^{(2)}$ values account for 12.9 and $30.5 \mathrm{kcal} \mathrm{mol}^{-1}$ for the $C_{\mathrm{i}}$ dimer of phosphonate dianion in the dichloromethane solution. Together with the more favoured interaction energy that was previously discussed, these data reveal a slight cooperative effect of the cyanostars on the stabilisation of the interanionic $\mathrm{H}$-bonds.

The $\mathrm{H}$-bonds between the $\mathrm{O}$ atoms in the phosphonates with the acidic hydrogen atoms in the $\mathrm{CH}$ functionalities of the cyanostars represent the interactions of $\mathrm{O}_{\mathrm{lp}} \rightarrow \sigma^{*}(\mathrm{CH})$ nature. Fig. 3 shows the most representative of them, with their orbital interactions accounting for 3.4, 4.1, and $8.1 \mathrm{kcal} \mathrm{mol}^{-1}$, and interatomic distances of 2.24, 2.23, and $1.99 \AA$, respectively.

An alternative analysis of the $\mathrm{H}$-bonds taking place between the phosphonate and the cyanostar units is given by Bader's atoms 


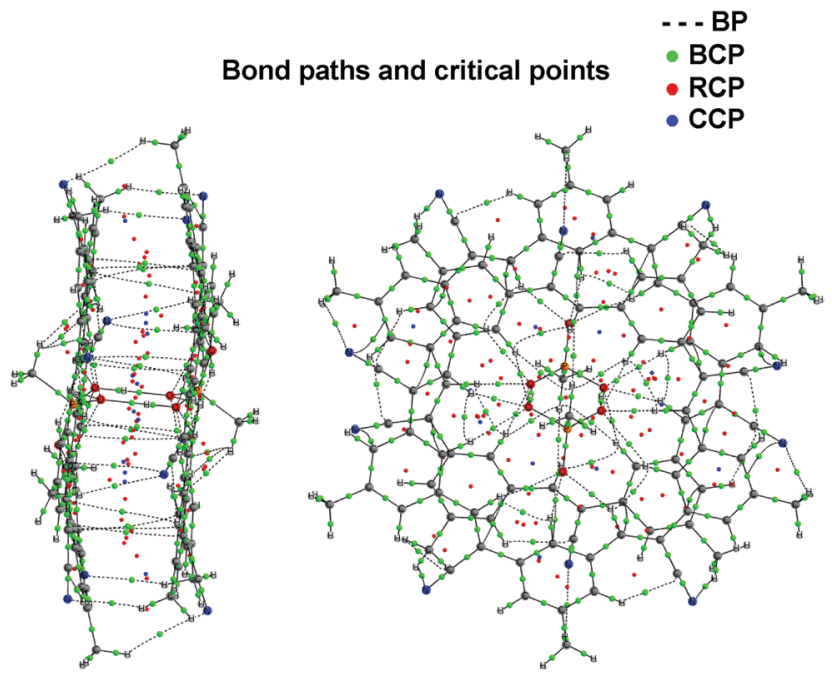

Fig. 4 AIM analysis of the phosphonate: cyanostar minimum (in dichloromethane) shown in Fig. 2. BP, BCP, RCP, and CCP refer to the bond path, and bond, ring, and cage critical points, respectively.

in molecules (AIM) theory. As seen in Fig. 4, the solid and dashed lines represent the bond paths in which the electron density, $\rho$, at the bond critical point (BCP, in green) is larger or smaller than 0.05 a.u. - this representing a reasonable cut-off, which can be considered for the existence of strong or weak interactions. Thus, interanionic $\mathrm{O}-\mathrm{H} \cdots \mathrm{O}^{-} \mathrm{H}$-bonds are characterised to be strong chemical contacts with a $\rho$ value of $5.28 \times 10^{-2}$ a.u. However, the most relevant aspect is given by the numerous presence of BCPs connecting the $\mathrm{O}$ atoms and the acidic hydrogens from $\mathrm{C}\left(\mathrm{sp}^{2}\right) \mathrm{H}$ groups, revealing the existence of an intricate network of moderate H-bonds between cyanostar macrocycles and phosphonates. Based on these data, it can be deduced that these $\mathrm{H}$-bonds are weaker than IAHBs with $\rho$ values smaller than $2.50 \times 10^{-2}$ a.u.

Interestingly, linear correlations have been described between AIM and NBO properties for such $\mathrm{C}\left(\mathrm{sp}^{2}\right) \mathrm{H} \cdots \mathrm{O} \mathrm{H}$-bonds. Considering electron density values, $\rho$, and its Laplacian, $-\nabla^{2} \rho$, at the BCPs $v s$. orbital interaction energies, $E^{(2)}$, coefficients of determination $\left(R^{2}\right)$ account for 0.91 and 0.92 , respectively, clearly indicating a strong linear correlation between both properties despite their different nature: one is topological based on electronic density (AIM), and the other is orbital (NBO) (see Fig. 5).

We have also examined the effect of the size of the aliphatic chain of the phosphonate anions and the role it might play in the stabilisation. According to the data, the interaction energies slightly increase if a larger alkyl group in placed on each phosphonate, which indicates a greater dispersion of the negative charge. However, this effect is really minor since for the case of the $2: 2$ aggregate between hydrogen hexylphosphonate and cyanostar in dichloromethane, $E_{\mathrm{int}}^{(1)}$ and $E_{\mathrm{int}}^{(2)}$ only decrease by 0.1 and $0.8 \mathrm{kcal} \mathrm{mol}^{-1}$, respectively, with respect the relative one of hydrogen methylphosphonate (the one shown in Fig. 2).

This behaviour is not only characteristic of anionic dimers of phosphonates, since we have also observed similar trends in

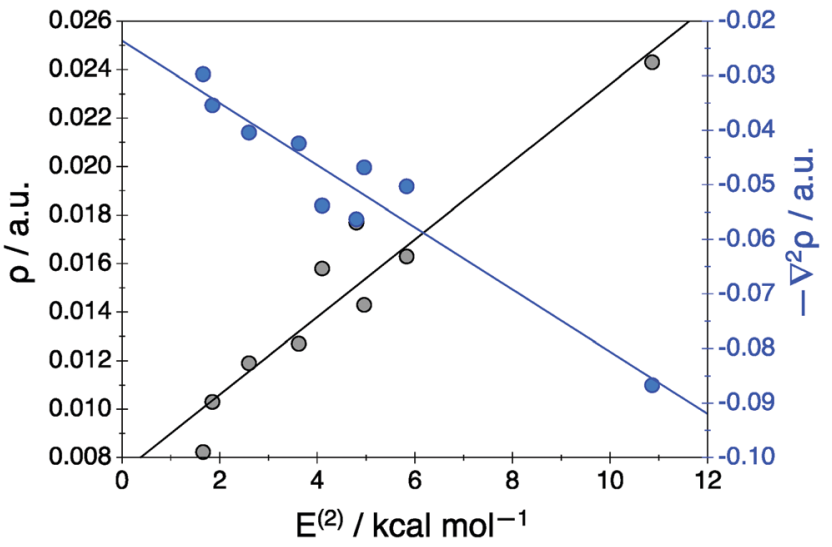

Fig. 5 Correlation between the electron density, $\rho$, and its Laplacian, $-\nabla^{2} \rho$, at the BCPs (AIM) vs. orbital interaction energies (NBO) for the $\mathrm{C}\left(\mathrm{sp}^{2}\right) \mathrm{H} \ldots \mathrm{O} \mathrm{H}$-bonds.


Fig. 6 Optimised 2:2 stoichiometric anion: cyanostar complexes for a series of common oxyacids. IAHBs distances are shown in $\AA$.

a series of anionic dimers of common oxyacids (see Fig. 6). Specifically, we have studied the 2:2 stoichiometric anion: cyanostar complexes with (di)hydrogen borate, carbonate, phosphate, arsenate, sulphate, and selenate, all in dichloromethane solution. As a general behaviour, anionic H-bond distances show similar values and practically do not differ in the six selected cases (values between 1.60 and $1.65 \AA$ ). However, differences in the electronic interaction energies (see Table S1 in the ESI $\dagger$ ) are more pronounced. For this series, $E_{\text {int }}^{(1)}$ is $-26.7 \mathrm{kcal} \mathrm{mol}^{-1}$ for the $2: 2 \mathrm{H}_{2} \mathrm{PO}_{4}{ }^{-}$: CS system, while for the supramolecular complex in which two CS macrocycles trap two hydrogen selenate anions, it is $-21.6 \mathrm{kcal} \mathrm{mol}^{-1}$. Similarly, the lowest value of $E_{\mathrm{int}}^{(2)}$ is also for the $2: 2 \mathrm{H}_{2} \mathrm{PO}_{4}{ }^{-}$: CS aggregate, $-32.6 \mathrm{kcal} \mathrm{mol}^{-1}$, while for the $2: 2 \mathrm{HSeO}_{4}{ }^{-}: \mathrm{CS}$ complex this is the highest, $-25.5 \mathrm{kcal} \mathrm{mol}^{-1}$. Given these differences, we can conclude that cyanostar macrocycles could 
be proposed as selective materials for the capture of inorganic anions with potential application in water decontamination.

\section{Conclusions}

In summary, anionic dimers, amongst which are included phosphonates, are stabilised when trapped inside the cavities of cyanostar macrocycles. Based on our results, electronic interaction energies, computed as the difference in energy between the supramolecular system and each one of its anion: cyanostar dimeric and monomeric units in dichloromethane solution, account for -25.7 and $-37.6 \mathrm{kcal} \mathrm{mol}^{-1}$, respectively, for the 2:2 $\mathrm{PH}$ : cyanostar aggregate, in which $\mathrm{PH}$ represents the hydrogen methylphosphonate anion. This stabilisation is mainly due to the presence of three types of interactions: two interanionic $\mathrm{H}$-bonds linking the phosphonate units, the $\pi-\pi$ stacking between the two cyanostars, and a series of $\mathrm{C}\left(\mathrm{sp}^{2}\right) \mathrm{H} \cdots \mathrm{O}$ noncovalent interactions creating an intricate network of $\mathrm{H}$-bonds between the cyanostar macrocycle and the dimeric phosphonates. The latter ones cooperatively reinforce the interanionic $\mathrm{H}$-bonds in both dichloromethane and water solutions. Finally, we hope that our results might stimulate further interest in the chemistry of interanionic H-bond (IAHB) complexes.

\section{Conflicts of interest}

There are no conflicts to declare.

\section{Acknowledgements}

L. M. A. is a ULPGC Postdoc Fellow and thanks Universidad de Las Palmas de Gran Canaria (ULPGC). J. E. and I. A. acknowledge the Ministerio de Ciencia, Innovación y Universidades (PGC2018-094644-B-C22) and Comunidad Autónoma de Madrid (P2018/EMT-4329 AIRTEC-CM) for their support. Gratitude is also due to the KAUST Supercomputing Laboratory using the supercomputer Shaheen II and the CTI (CSIC) for providing the computational resources.

\section{Notes and references}

1 J. D. Watson and F. H. C. Crick, Nature, 1953, 171, 737-738.

2 R. E. Hubbard and M. K. Haider, eLS, 2010, DOI: 10.1002/ 9780470015902.a0003011.pub2.

3 K. Autumn, M. Sitti, Y. A. Liang, A. M. Peattie, W. R. Hansen, S. Sponberg, T. W. Kenny, R. Fearing, J. N. Israelachvili and R. J. Full, Proc. Natl. Acad. Sci. U. S. A., 2002, 99, 12252.

4 G. Cavallo, P. Metrangolo, R. Milani, T. Pilati, A. Priimagi, G. Resnati and G. Terraneo, Chem. Rev., 2016, 116, 2478-2601.

5 M. H. Kolář and P. Hobza, Chem. Rev., 2016, 116, 5155-5187.

6 D. J. Pascoe, K. B. Ling and S. L. Cockroft, J. Am. Chem. Soc., 2017, 139, 15160-15167.

7 L. Vogel, P. Wonner and S. M. Huber, Angew. Chem., Int. Ed., 2019, 58, 1880-1891.

8 S. Scheiner, Acc. Chem. Res., 2013, 46, 280-288.
9 J. E. Del Bene, I. Alkorta and J. Elguero, in Noncovalent Forces, ed. S. Scheiner, Springer International Publishing, Cham, 2015, pp. 191-263, DOI: 10.1007/978-3-319-14163-3_8.

10 I. Alkorta, I. Rozas and J. Elguero, J. Phys. Chem. A, 2001, 105, 743-749.

11 A. Bauzá, T. J. Mooibroek and A. Frontera, Angew. Chem., Int. Ed., 2013, 52, 12317-12321.

12 A. Bauzá and A. Frontera, Angew. Chem., Int. Ed., 2015, 54, 7340-7343.

13 I. Alkorta, J. Elguero and A. Frontera, Crystals, 2020, 10, 180.

14 E. Arunan, G. R. Desiraju, A. Klein Roger, J. Sadlej, S. Scheiner, I. Alkorta, C. Clary David, H. Crabtree Robert, J. Dannenberg Joseph, P. Hobza, G. Kjaergaard Henrik, C. Legon Anthony, B. Mennucci and J. N. David, Pure Appl. Chem., 2011, 83, 1637.

15 E. Arunan, G. R. Desiraju, A. Klein Roger, J. Sadlej, S. Scheiner, I. Alkorta, C. Clary David, H. Crabtree Robert, J. Dannenberg Joseph, P. Hobza, G. Kjaergaard Henrik, C. Legon Anthony, B. Mennucci and J. N. David, Pure Appl. Chem., 2011, 83, 1619.

16 S. Scheiner, Struct. Chem., 2019, 30, 1119-1128.

17 S.-W. Lee and J. L. Beauchamp, J. Am. Soc. Mass Spectrom, 1999, 10, 347-351.

18 L. Feketeová and R. A. J. O'Hair, Chem. Commun., 2008, 4942-4944, DOI: 10.1039/B808124G.

19 S. R. Kass, J. Am. Chem. Soc., 2005, 127, 13098-13099.

20 A. Shokri, M. Ramezani, A. Fattahi and S. R. Kass, J. Phys. Chem. A, 2013, 117, 9252-9258.

21 F. Weinhold and R. A. Klein, Angew. Chem., 2014, 126, 11396-11399.

22 I. Mata, E. Molins, I. Alkorta and E. Espinosa, J. Phys. Chem. A, 2015, 119, 183-194.

23 I. Mata, I. Alkorta, E. Molins and E. Espinosa, ChemPhysChem, 2012, 13, 1421-1424.

24 L. M. Azofra, J. Elguero and I. Alkorta, J. Phys. Chem. A, 2020, 124, 2207-2214, DOI: 10.1021/acs.jpca.9b10681.

25 D. Braga, F. Grepioni and J. J. Novoa, Chem. Commun., 1998, 1959-1960, DOI: 10.1039/A804392B.

26 T. Steiner, Chem. Commun., 1999, 2299-2300, DOI: 10.1039/ A905966K.

27 P. Macchi, B. B. Iversen, A. Sironi, B. C. Chakoumakos and F. K. Larsen, Angew. Chem., Int. Ed., 2000, 39, 2719-2722.

28 M. Mascal, C. E. Marjo and A. J. Blake, Chem. Commun., 2000, 1591-1592, DOI: 10.1039/B002361M.

29 E. M. Fatila, E. B. Twum, A. Sengupta, M. Pink, J. A. Karty, K. Raghavachari and A. H. Flood, Angew. Chem., Int. Ed., 2016, 55, 14057-14062.

30 E. M. Fatila, E. B. Twum, J. A. Karty and A. H. Flood, Chem. - Eur. J., 2017, 23, 10652-10662.

31 W. Zhao, B. Qiao, C.-H. Chen and A. H. Flood, Angew. Chem., Int. Ed., 2017, 56, 13083-13087.

32 J. R. Dobscha, S. Debnath, R. E. Fadler, E. M. Fatila, M. Pink, K. Raghavachari and A. H. Flood, Chem. - Eur. J., 2018, 24, 9841-9852.

33 E. M. Fatila, M. Pink, E. B. Twum, J. A. Karty and A. H. Flood, Chem. Sci., 2018, 9, 2863-2872. 
34 L. González, F. Zapata, A. Caballero, P. Molina, C. Ramírez de Arellano, I. Alkorta and J. Elguero, Chem. - Eur. J., 2016, 22, 7533-7544.

35 P. Sabater, F. Zapata, A. Caballero, I. Alkorta, C. Ramirez de Arellano, J. Elguero and P. Molina, ChemistrySelect, 2018, 3, 3855-3859.

36 W. Zhao, B. Qiao, J. Tropp, M. Pink, J. D. Azoulay and A. H. Flood, J. Am. Chem. Soc., 2019, 141, 4980-4989.

37 C. Adamo and V. Barone, J. Chem. Phys., 1999, 110, 6158-6170.

38 R. Ditchfield, W. J. Hehre and J. A. Pople, J. Chem. Phys., 1971, 54, 724-728.

39 A. Klamt and G. Schüürmann, J. Chem. Soc., Perkin Trans. 2, 1993, 799-805.

40 T. H. D. Jr., J. Chem. Phys., 1989, 90, 1007-1023.

41 M. Valiev, E. J. Bylaska, N. Govind, K. Kowalski, T. P. Straatsma, H. J. J. Van Dam, D. Wang, J. Nieplocha, E. Apra, T. L. Windus and W. A. de Jong, Comput. Phys. Commun., 2010, 181, 1477-1489.

42 F. Weinhold, C. R. Landis and E. D. Glendening, Int. Rev. Phys. Chem., 2016, 35, 399-440.

43 M. J. Frisch, G. W. Trucks, H. B. Schlegel, G. E. Scuseria, M. A. Robb, J. R. Cheeseman, G. Scalmani, V. Barone,
B. Mennucci, G. A. Petersson, H. Nakatsuji, M. Caricato, X. Li, H. P. Hratchian, A. F. Izmaylov, J. Bloino, G. Zheng, J. L. Sonnenberg, M. Hada, M. Ehara, K. Toyota, R. Fukuda, J. Hasegawa, M. Ishida, T. Nakajima, Y. Honda, O. Kitao, H. Nakai, T. Vreven, J. A. Montgomery Jr., J. E. Peralta, F. Ogliaro, M. Bearpark, J. J. Heyd, E. Brothers, K. N. Kudin, V. N. Staroverov, R. Kobayashi, J. Normand, K. Raghavachari, A. Rendell, J. C. Burant, S. S. Iyengar, J. Tomasi, M. Cossi, N. Rega, N. J. Millam, M. Klene, J. E. Knox, J. B. Cross, V. Bakken, C. Adamo, J. Jaramillo, R. Gomperts, R. E. Stratmann, O. Yazyev, A. J. Austin, R. Cammi, C. Pomelli, J. W. Ochterski, R. L. Martin, K. Morokuma, V. G. Zakrzewski, G. A. Voth, P. Salvador, J. J. Dannenberg, S. Dapprich, A. D. Daniels, Ö. Farkas, J. B. Foresman, J. V. Ortiz, J. Cioslowski and D. J. Fox, Gaussian09 (revision D.01), Gaussian, Inc., Wallingford CT, 2009.

44 T. A. Keith, AIMAll (Version 11.10.16), TK Gristmill Software, Overland Park KS, USA, 2011.

45 S. M. Chalanchi, I. Alkorta, J. Elguero and D. Quiñonero, ChemPhysChem, 2017, 18, 3462-3468.

46 S. Lee, C.-H. Chen and A. H. Flood, Nat. Chem., 2013, 5, 704. 